It has also been said that if palliative care is developed, euthanasia will not be needed. Effective palliative care will keep all patients free of pain so no one will ask for euthanasia. I believe that the claim that pain can always be defeated is false (unless you sedate the patient into oblivion), but this is really not what the discussion is or should be about. Patients may request euthanasia for reasons other than pain. Some patients find that they are finished with their lives and their process of dying. They find it humiliating to have to continue living, experiencing mental and physical decay. If there are such patients, and I believe there are, it is cruel to turn down their request for euthanasia. A system for euthanasia would mean that people could approach the terminal phase of their lives without fear. They would know that, if, when their turn comes, and things turn out to be terrible, they have a way out.

Contributors and sources: TT has published extensively in moral philosophy, political philosophy, and medical ethics. The three views are discussed more fully in his book Understanding Ethics (Edinburgh University Press, 2002).

Competing interests: None declared.

(Accepted 6 July 2005)

\title{
Dutch experience of monitoring euthanasia
}

\author{
Bregje D Onwuteaka-Philipsen, Agnes van der Heide, Martien T Muller, Mette Rurup, \\ Judith A C Rietjens, Jean-Jacques Georges, Astrid M Vrakking, Jacqueline M Cuperus-Bosma, \\ Gerrit van der Wal, Paul J van der Maas
}

Physician assisted death is known to occur in several countries, ${ }^{1-5}$ and probably takes place in others, albeit with different frequencies. Three places have enacted a notification procedure to safeguard this practice: Oregon in the United States, Belgium, and the Netherlands. ${ }^{6-8}$ In the United Kingdom, a law on assisted dying for the terminally ill has been proposed and has stimulated much discussion. ${ }^{9-11}$ The Netherlands has had a formal procedure for reviewing cases of euthanasia and physician assisted suicide since 1991. The procedure has been evaluated and revised twice. ${ }^{12}$ We examine how well the Dutch system has ensured best practice and reporting of physician assisted suicide. Although the Dutch experience cannot solve the question whether legal regulation of assisted dying is desirable, it gives insight into the possibilities of achieving transparency, public oversight, and legal control.

\section{Review procedure}

In the Dutch review procedure, euthanasia is defined as purposely ending the life of someone at his or her explicit request. Physician assisted suicide is defined as the prescription or supply of drugs with the explicit intention to enable the patient to end his or her own life. The review procedure aims to stimulate disclosure of cases and ensure verifiability, and adherence to the requirements for prudent practice.

The first review procedure was introduced in 1991 and was legally enacted in 1994. Doctors were required to report cases to the public prosecutor (through the medical examiner). The public prosecutor carried out an initial review and then referred cases to the Assembly of Prosecutors General and the minister of justice for final review. Euthanasia and physician assisted suicide were punishable, but doctors could expect not to be prosecuted if they met the requirements for prudent practice. This procedure was evaluated in 1996, and a new system introduced in $1998 .^{6}$

Under the revised procedure doctors had to report to one of five regional review committees (through the medical examiner). These committees, consisting of a lawyer, an ethicist, and a physician, reviewed reported cases and advised the Assembly of Prosecutors General. The assembly still made the ultimate decision on whether to prosecute, and euthanasia and physician assisted suicide remained illegal.

In April 2002 a new law on euthanasia was enacted that established a revised review procedure. The review committee still examines all reported cases, but only those that do not meet the requirements for prudent practice are subsequently reviewed by the Assembly of Prosecutors General. The committee can request extra information from the reporting doctor if required. Euthanasia and physician assisted suicide are legal provided that the requirements for prudent practice are met.

The central question for review in all three procedures has been whether the requirements for prudent practice have been met. These have not been altered (box).

\section{Effect on notification}

The success of the review procedure depends largely on the extent to which doctors report euthanasia and physician assisted suicide. The figure shows the numbers of reported cases between 1990 and 2004.

Dutch requirements for prudent practice in euthanasia and physician assisted suicide ${ }^{1314}$

Substantive requirements

- The patient's request must be voluntary and well considered

- The patient's condition must be unbearable and hopeless

- No acceptable alternatives for treatment are available

- The method is medically and technically appropriate

Procedural requirements

- Another doctor is consulted before proceeding

- The case is reported as an unnatural death
Department of Public and Occupationa Health, Institute for Research in Extramural Medicine, VU University Medical Centre, 1081 BT Amsterdam, Netherlands Bregje D Onwuteaka-Philipsen health scientist Martien T Muller social gerontologist Mette Rurup medical biologist Jean-Jacques Georges nursing scientist Jacqueline M Cuperus-Bosma lawyer

Gerrit van der Wal professor of social medicine

Department of Public Health, Erasmus MC, University Medical Centre, Rotterdam, Netherlands

Agnes van der Heide

epidemiologist

Judith A C Rietjens health scientist Astrid M Vrakking sociologist

Paul J van der Maas professor of social medicine

Correspondence to: B D Onwuteaka-

Philipsen

b.philipsen@vumc.nl

BMJ 2005;331:691-3 
The numbers increased from 480 in 1990 (before the review procedure) to 1460 in 1995 and 2216 until 1999; the numbers decreased during 2001 to 2003, but rose again in 2004. To interpret these numbers we need to know the total number of cases of euthanasia and physician assisted suicide (reported and unreported). We conducted accurate large scale and anonymous research among doctors in 1990, 1995, and 2001 to obtain an estimate of total cases. ${ }^{15}$ A written questionnaire was sent to the attending doctors of a large random sample of deceased patients identified from death certificates. We obtained responses from 5197 doctors in 1990 (76\%), 5146 in 1995 (77\%), and 5617 in 2001 (74\%). Strict criteria were used to define a death as euthanasia to avoid underestimation of cases.

The notification rate increased from $18 \%$ in 1990 to $54 \%$ in 2001 (table). Although the notification rate clearly increased after the first review procedure was introduced, the modification in 1998 seems to have had only a limited effect. We cannot tell from the available data whether the fall in reported cases since 1999 is due to a decrease in notification or in the occurrence of euthanasia and physician assisted suicide. Further research planned for 2005-6 should provide more insight into this question.

\section{Do reported cases differ?}

The data in the table show that almost half of all cases of euthanasia and physician assisted suicide are still not reported. The reason for this is unclear, but it would be especially disturbing if reported cases differed systematically from unreported cases. Van der Wal and colleagues conducted extensive interviews with a random sample of doctors who were guaranteed immunity from prosecution in 1996 (405 doctors, response rate $98 \%)$ and $2002(410$, response 85\%). Comparison with the 1995 study of reported cases showed no major differences in patient characteristics and clinical conditions between reported and unreported cases. In both groups most patients had cancer and an estimated life expectancy of one month or less. There were also no differences in the extent to which the substantive requirements were met, but in the unreported cases the attending doctors were less likely

Total number of cases of euthanasia and physician assisted suicide, number of reported cases, and notification rates, Netherlands 1990, 1995, and 2001

\begin{tabular}{|c|c|c|c|c|}
\hline & \multicolumn{3}{|c|}{ Specialty } & \multirow[b]{2}{*}{ Total } \\
\hline & $\begin{array}{c}\text { General } \\
\text { practitioners }\end{array}$ & $\begin{array}{c}\text { Medical } \\
\text { specialists }\end{array}$ & $\begin{array}{l}\text { Nursing home } \\
\text { physicians }\end{array}$ & \\
\hline \multicolumn{5}{|l|}{ 1990: } \\
\hline All cases & NA & NA & NA & 2700 \\
\hline Reported cases & NA & NA & NA & 486 \\
\hline Notification rate $(95 \% \mathrm{Cl})$ & NA & NA & NA & 18 (16 to 23 ) \\
\hline \multicolumn{5}{|l|}{ 1995: } \\
\hline All cases & 2625 & 900 & 75 & 3600 \\
\hline Reported cases & 1163 & 274 & 26 & 1463 \\
\hline Notification rate $(95 \% \mathrm{Cl})$ & 44 & 30 & 35 & 41 (35 to 49$)$ \\
\hline \multicolumn{5}{|l|}{ 2001: } \\
\hline All cases & 2925 & 775 & 100 & 3800 \\
\hline Reported cases & 1761 & 252 & 41 & 2054 \\
\hline Notification rate $(95 \% \mathrm{Cl})$ & 60 & 33 & 41 & $54(50-67)$ \\
\hline
\end{tabular}

$\mathrm{NA}=$ not available to have consulted a second doctor or written a report on the decision. ${ }^{6}$

This relation between consultation and notification was also found in the evaluation of the support and consultation on euthanasia project in the Netherlands. This project provides specifically trained, independent, and knowledgeable general practitioners as consultants for general practitioners who are considering whether to grant a request for euthanasia. In four districts the notification rate could be calculated before and one and half years after the introduction of a network of consultants. ${ }^{16}$ The notification rate increased from $52 \%$ to $66 \%$ in this time. ${ }^{12}$ The introduction of this network for all Dutch general practitioners, together with the fact that general practitioners receive most requests for euthanasia and assisted suicide, probably explains why a large proportion of the increase in notification rate between 1995 and 2001 is among general practitioners (table). The consultation network began to be expanded to hospitals and nursing homes in 2004, and this may increase the notification rate among other doctors.

\section{Review of cases}

Review of cases is generally based on a written report by the doctor detailing the decision making process and requirements for prudent practice (usually using a standard form), a report from the consulting doctor, and relevant parts of the medical records. Only the cases in which there is doubt about whether the requirements for prudent practice have been met are discussed in the review committee and assembly meetings. In 2000-1, the review committees asked for extra information from the reporting doctor in $5 \%$ of cases (3.5\% by letter, $1 \%$ by telephone, and $0.5 \%$ by doctor) and from the consultant in $2 \%$ of cases. ${ }^{14}$ The committees reported a negative judgment to the Assembly of Prosecutors General in seven cases $(0.1 \%)$. The assembly discussed four of these cases. The other three cases were referred because the doctor had not consulted an independent doctor before acting, and the assembly took into account the difficulty of finding another doctor in remote areas at that time. The assembly also discussed 27 cases that the review committees referred with a positive judgment. In two of these cases the assembly started an inquest (one led to acquittal; whether the other one will lead to prosecution is not yet known). The other cases were acquitted without an inquest being started. ${ }^{12}$

The main reasons for a review committee discussing a case before April 2002 were questions about the consultation (44\%) and about the patient's condition being hopeless and unbearable (39\%). Both reasons were mentioned less frequently in cases discussed by the Assembly of Prosecutors General before the review committees were set up in 1998 (24\% and $25 \%$ ). The review committees seem to be carrying out more thorough reviews and are discussing not only more cases but more topics (especially medical issues).$^{12}$ Since the introduction of review committees, the number of cases discussed by the prosecutors general has decreased. This might be because the review committees can request extra information from the reporting doctor or the consultant when they need it. This reduction in the number of cases discussed and 
the number of inquests started by the assembly might make doctors feel less like criminals and less afraid of prosecution.

\section{Doctors' experiences and opinions}

The success of the review procedure depends on the willingness of doctors to report euthanasia. Doctors who reported a case to a review committee in 2001 mentioned negative experiences less frequently than doctors who reported a case to the public prosecutors. The two most mentioned negative experiences were "time consuming" (18\% v 38\% in 1995) and "burdensome" ( $16 \%$ v 32\% in 1995). Most doctors who had reported a case to both the review committee and the public prosecutors thought that the review committee improved the time between reporting and receiving the judgment, explanation of the judgment, the clarity of the procedure, and the quality of the judgment. ${ }^{12}$

Most doctors thought that the presence of a doctor on the committee, the need for the committee to explain their judgment to the reporting doctor, and the fact that a review committee is placed between the doctor and the public prosecutor were an improvement on the previous procedure. In addition, most thought that review committee procedure would help to achieve better oversight and control of euthanasia and physician assisted suicide. ${ }^{12}$

\section{Success of review procedure}

Despite two decades of relatively open euthanasia practice and implementation of a review procedure, in 2001 almost half of cases were still not reported. The reason for this is uncertain. The limited rise in the notification rate between 1995 and 2001 suggests that the introduction of the review committee did not bring as much improvement in reporting as expected. This is remarkable since doctors' opinions of this new procedure were positive and those that had reported to a review committee generally had no negative experiences. However, the chance of doctors being contacted for further information increased with the change to the review committees. Although the risk of prosecution did not increase, this might have made doctors hesitant to report. Ongoing education might help increase doctors' awareness of whether and when they have to report a case, how to meet the requirements for prudent care, and help them to realise that the chances of prosecution are close to zero if they comply with the requirements.

The drop in reported cases since 2000 also raises questions about the effectiveness of the review committees. Until a new notification rate can be calculated, we cannot tell whether the drop reflects a fall in notification rate or a decrease in euthanasia and physician assisted suicide. The rise in reported cases in 2004 might, if it is not coincidental, indicate that the further shift in the focus of the review process from repressive (by the public prosecutor) to educative (through review committees) has been effective. If the total cases of euthanasia and physician assisted suicide has fallen rather than notification it shows that the review procedure has not increased the practice of euthanasia. Euthanasia might have fallen because of improvements in palliative care in the Netherlands in recent

\section{Summary points}

The Netherlands has had a review procedure for euthanasia and physician assisted suicide since 1991

Although the system has increased reporting, around half of cases remain unreported

Non-reporting seems to be associated with a lack of consultation with another doctor

Introduction of reporting to review committees rather than the public prosecutor has had a limited effect on notification despite doctors' positive opinions

years and the introduction of terminal sedation, which could sometimes be used as an alternative for euthanasia and physician assisted suicide. ${ }^{17} 18$

Contributors and sources: This article is based on official documents of the review procedures, on the official position of Dutch doctors on the subject, and on the reports of the three evaluation studies. All the authors participated in the evaluation of the euthanasia review procedure in 2001-2, and several of them participated in the earlier evaluations. BDO-P wrote the manuscript. All other authors critically commented on several drafts of the manuscript, including the final version.

Competing interests: None declared.

1 Emanuel EJ. Euthanasia and physician-assisted suicide. A review of the empirical data from the United States. Arch Intern Med 2002;162:142-52. Ward BJ, Tate PA,. Attitudes among NHS doctors to requests for euthanasia. BMJ 1994;308:1332-4.

euthanasia. BMJ 1994;308:1332-4.
Førde R, Aasland OG, Falkum E. The ethics of euthanasia-attitudes and practice among Norwegian physicians. Soc Sci Med 1997;45:887-92.

4 Kirschner R, Elkeles T. Patterns of performance by German physicians and their opinions regarding euthanasia. Gesundheitswesen 1998;60:24753.

5 Van der Heide A, Deliens L, Faisst K, Nilstun T, Norup M, Paci E, et al. End-of-life decision-making in 6 European countries. Lancet 2003;362:345-50.

6 Van der Wal G, van der Maas PJ, Bosma JM, Onwuteaka-Philipsen BD, Willems DL, Haverkate I, et al. Evaluation of the notification procedure for physician-assisted death in the Netherlands. $N$ Engl J Med for physician-ass

7 Hedberg K, Hopkins D, Kohn MK. Five years of legal physician-assisted suicide in Oregon. N Engl J Med 2003;348:961-4.

8 Watson R. Belgium gives terminally ill the right to die. BMJ 2001;323:1024.

9 Dyer O. Parliament to look again at issue of "assisted dying" for terminally ill patients. BMJ 2003;327:1186.

10 House of Lords Select Committee on the Assisted Dying for the Terminally Ill Bill. Assisted dying for the terminally ill bill: first report. London: Stationery Office, 2005.

11 Huxtable R. Assisted suicide, we need to clarify the current legal compromise but preserve the lenient attitude. BMJ 2004;328:1088-9.
maxted

12 Van der Wal G, van der Maas PJ, Onwuteaka-Philipsen BD, van der Heide A. Medical decision-making at the end of life. The practice and the euthanasia notification procedure [in Dutch]. The Hague: Sdu Publishers, 2003.

13 Board of the Royal Dutch Medical Association. Concerning euthanasia [in Dutch]. Utrecht: RDMA, 2003.

14 Regional Review Committee Euthanasia. Annual report 2003 [in Dutch]. The Hague: Albani, 2004.

15 Onwuteaka-Philipsen BD, van der Heide A, van der Koper D, Keij-Deerenberg I, Rietjens JA, Rurup ML, et al. Euthanasia and other end-of-life decisions in the Netherlands in 1990, 1995 and 2001. Lancet 2003;362:395-9.

16 Jansen-van der Weide MC, Onwuteaka-Philipsen BD, van der Wal G. Jansen-van der Weide MC, Onwuteaka-Philipsen BD, van der Wal G.
Implementation of the project support and consultation for general Implementation of the project support and consultation for general
practitioners concerning euthanasia in the Netherlands. Health Policy practitioners con

17 Rietjens JAC, van der Heide A, Vrakking AM, Onwuteaka-Philipsen BD, van der Maas PJ, van der Wal G. Physician reports of terminal sedation without hydration or nutrition for patients nearing death in the Netherlands. Ann Intern Med 2004:141:178-85.

18 Gordijn B, Janssens R. Euthanasia and palliative care in the Netherlands: an analysis of the latest developments. Health Care Analysis 2004;12:195207.

(Accepted 11 June 2005) 